\title{
Hooked: How Politics Captures People's Interest By Markus Prior
}

\author{
Sukri Tamma
}

Hasanuddin Universty, Indonesia. Email: sukritamma@unhas.ac.id

\begin{tabular}{|c|c|}
\hline ARTICLE INFO & ABSTRACT \\
\hline $\begin{array}{l}\text { Keywords: } \\
\text { Interest; politic; } \\
\text { democracy; influence. } \\
\text { How to cite: } \\
\text { Tamma, S. (2021). Hooked: } \\
\text { How Politics Captures } \\
\text { People's Interest By Markus } \\
\text { Prior. ETNOSIA: Jurnal } \\
\text { Etnografi Indonesia. 6(1): } 1 \\
\text { - 8. } \\
\text { DOI: } \\
\text { 10.31947/etnosia.v6i1.13465 }\end{array}$ & $\begin{array}{l}\text { This article aims to review a book entitled Hooked: How Politics } \\
\text { Captures People's Interest (2018). This book is a work that tries to } \\
\text { show how this interest in politics arises under several conditions. This } \\
\text { book shows how several aspects are important factors in shaping one's } \\
\text { interest in politics. Based on research data conducted from four } \\
\text { countries that are claimed to be democratic countries, namely the } \\
\text { United States, United Kingdom, Germany, and Switzerland, this book } \\
\text { shows data on the conception of political interest by examining the } \\
\text { influence of aspects of education, profession, and the position of } \\
\text { parents. as well as ownership of certain income. This book succeeds } \\
\text { in offering a fairly comprehensive analysis in understanding how } \\
\text { human interest in politics can be formed. }\end{array}$ \\
\hline
\end{tabular}

\section{Introduction}

Generally, political interest is often understood only in terms of people's interest in participating in voting activities and several other political activities (Prior 2010). Political interest is one of the terms in the study of political science as the strongest predictor of "good citizenship", but almost nothing is known about that statement. For the first time in more than three decades, here's a study that sheds light on what political interest is, where it comes from, and why it matters. Providing the most comprehensive description of political interests in four Western democracies countries which are the United States, the United Kingdom, Germany, and Switzerland, this study analyzes large household panel datasets rarely used in political science to explain how interest develops in people's lives.

In an accessible way, this book's analytical approach encourages applied social scientists to consider how panel data could be used to better understand political behavior. It does so in a way that does not mask complexity and explains it in direct language. The advanced statistical methods are presented informally, accompanied by graphic illustrations that do not require prior knowledge to understand the methods used. The first book in over thirty years to study political interest, and the first-ever publication that explains why some people are more interested in politics than others. There has 
been neither agreement from experts nor works that comprehensively explain this issue. Therefore, this book entitled How Politics Captures People's Interest by Markus Prior tries to provide the answer to that condition.

\section{Discussion}

People's interest in politics makes people different, some people are interested in politics more deeply even though some are only interested in the superficial aspects. Besides, some people were completely uninterested. The studies conducted in a few countries showed that there are different categories of interest in politics, namely extremely interested, very interested, not interested at all, and slightly interested. However, only political interests are present in membership in the context of the self-governing class. This self-governing class is a segment where people contribute to joint decisions about how the state should be run. Political interest is not a requirement to join the selfgoverning class because some people have an interest in politics without having to be involved in the tasks of structuring society. Therefore, this book attempts to show a link between political interest and political involvement.

If, the limits of the self-governing class are not defined based on the standard requirements, personal qualifications, and reasons of ability but for reasons of interest in politics, then where does the political interest come from?. To be understood, the greater political interest does not make everyone an example of a good citizen. Because some people's opinions may become stronger but not wiser and higher political interest is also not enough to get rid of structural barriers to participation in the political space. But, in a balanced way, a greater political interest promises greater engagement and more effective self-governance, so how is political interest be built, the psychologists and education experts find ways to motivate individuals to carry out specific responsibility, but in politics, it is not viewed simply because political interest is different.

The foundation of how interest is formed and grows is seen as a challenge in research. The problem is interested in politics usually goes much deeper than it is seen. It makes it difficult to determine how specific political interests are formed. It seems related to the fact where many people have been interested in politics for a long time but at the same time, some changes occurred during that period because not much analysis could be done to see what caused the change in interest in politics. This is a challenge because understanding how political interest grows and develops is precisely related to this. Therefore, this book tries to show two important explanations related to what it means to be interested in politics and how we can explain how political interest can contribute to the self-governing class and develop its capacity.

Political interest consists of two types, the first is called situational interest. This type is usually associated with emotional reactions driven by something around the person that involves certain feelings about liking or wanting or not wanting from that object. the second type is dispositional interest. this type is something that is produced by the longterm sentiment that is very likely to persist even though the stimulant aspect is gone. In the context of the absence of an object that causes this type is usually associated with something that is inside a person. Dispositional interest usually arises from situational interest, but many of these situational interests are never sustainable when the causal 
aspect disappears. The entire content of this book seeks to show political interests related to dispositional and situational interests.

This book consists of three parts, the first part contains a description related to political interest, the second part shows how the development of political interest, the third explains the changes that may occur in political interest. The first part is consists of four subtitles, where the first is the psychology of political interest. This section begins with an attempt to answer basic questions of the political interest notion. This section lays down the basic meaning of political interest which is then used as a reference in the following sections.

The second subtitle in the first part is measuring political interest, in this section, some data is shown as evidence on political interest. The available data shows that people who are politically interested in one area of politics are usually also attracted to other areas of politics. The data show that the vast majority of people who are interested in politics are those who are interested in politics in large part must be interested more broadly in politics. One important aspect that is not asked in this section relates to campaigns and elections, However, this is explained in the next section.

The third part of this part is the Impacts of an election. This section shows that the earliest evidence of political interest is an enduring predisposition rather than a reaction to a situational cause. As the opening statement of this paper, a single measure of political interest cannot immediately distinguish between situational interest and dispositional interest. This section shows if people are asked a new example over time in terms of how interested they are in politics then the responses are usually very similar. It is premature to state that dispositional political interest is due to this evidence. It is because first, it may be related to other political events besides the election to see the possibility of fluctuating situational interest. Second, almost all of the political interest aggregately does not pay attention to instability at the individual level that can appear in the diagnosis at an enduring predisposition. Thus ensuring that individual is an opposite aspect to the aggregate of the population in terms of ensuring a constant level of political interest is necessary to ask it repeatedly to the same people. The key point of this section is not that political interest is not a one-dimensional thing but related to many variations on many dimensions.

Sub-section fourth trying to show the trend of political interest for decades. It is important to determine a unit of time in the analysis carried out. Two sets of plots look very similar in expressing the stagnant state of political interest over time. Aggregated political interests are of a moderate magnitude that has remained very stable over several decades. When several different questions were asked to compare several countries it was not accurate, but at the level of political interest on a moderate scale, it showed similarities in the four countries. the high aggregate stability of political interest not only in the four countries but also in several countries in the European region during the same period. The analysis in this section has raised tremendous concern regarding the effects panel. The trend of plotting the political interest of different countries on different graphs which is observed on sample differences without considering the effect of sampling error shows very small differences. 
By emphasizing the psychological model of interest so far the existing analysis shows that apolitical interest has affective and cognitive components and still exists despite negative assessments of politics. Cognitive facilitator of interest including the importance of the domain of interest and good feelings will influence people's expressions related to how much they are related to politics.

Part II of this book consists of three sub-titles. This section in general attempts to answer some important questions from several different perspectives. Questions like "Do the same people report similar levels of political interest over periods? in some analysis of several empirical facts will dispel the notion of a self-governing class constituted of politically interested individuals. The explanation related to this is then explained in succession through the existing sub-headings.

In the first part of this part, namely "Political interest over the life course: the population average" this paper shows that empirical analysis shows the importance of the Aging Hypothesis. However, the positive effect of aging on political interest diminishes of adults. Based on the analysis results of Brit, German and Swiss, it shows that the modest condition is significant, but there is a significant condition that the adolescence and early adulthoods are more interested. Furthermore, in these three countries, however, the period between mid-teens and mid-twenties clearly shows a significant developmental time. Thus, when teenagers enter the age of eighteen then they have become people who have further interests in politics. This shows that age development is also an important factor affecting political interest. this seems to be due to the implications of age differences in understanding political development.

The next section in this Part is "Stability and Variation in Political Interest". This section opens with a comparative statement with the previous section which shows that on average data from Britania, German, and Swiss political interest increased 10-15 points on a scale of 0-100 in adolescence and early adulthood before it came to a constant point. Through data presentation and graphs as the basis for the argument, this section shows that the variation in political interests is very large due to differences in the people on which it is focused. However, it can be smaller if you look at the differences in people who are relatively the same over time. This section explains the variations that occur from the two perspectives of the similarity of the political interest of different people and how strong a person's current political interest is about their political interest the following year.

One important thing that is shown in this section is the condition that since the initial assessment of childhood, then adolescence reaches early adulthood when political interest is still malleable. Especially in teenagers, the political interstitial is usually not stable. Their political interest conditions will stabilize when they are approaching their 20 s, and by the time of their early 30s, most of them have been able to identify their interest in politics. These results indicate the condition of the "impressionable years" model of socialization which indicates changes in political interest, especially in the early period of human age.

Although the results from this chapter indicate that changes in political interest in adults are not the same, they are consistent concerning isolated change in the context of smaller 
groups. Therefore, it still requires the question of what happens to the political interest of some adults who join political organizations or partner with them who have a related partner, has a greater chance of being interested in politics. Both of these are rare things, therefore the results of this chapter open up space for rare conditions of interest in politics, including for adults. At the end of this part, it shows a great variation on the way in politics. On average, interest in politics increased only in the period of adolescence and young adulthood. However, there are still a few people who do not develop or even lose interest in politics during this age period. Some other people show more interest while some of them were more interested even when they were young.

The third part of this book begins with writing about the Big benefits of panel data analysis, in this chapter, it is explained what things can be learned more with the implications when we measure what might cause or be implications of repetitive processes. -repeat. The analysis approach in the third section is mainly focused on causality, it gives rise to a change in one variable used and on the replacement of another variable. This section shows that the existing data panels make it possible to measure it. When the potential variable that will be measured varies over time for a person, it is possible to observe if changes that occur in certain variables are followed by changes in the individual's political interest. It shows dynamics in the context of analysis that showed in this section. The dynamics in this section indicate that there are categorical differences between cross-sectional and longitudinal data.

The details of the panel design in this section of observations made more than once on individuals with the same level of characteristics will raise a fundamental challenge in the form of the ability to relate changes to the level of a particular variable. In simple terms, this analysis will mainly direct our focus when it comes to the point where it should be considered the factors that may be important influencing the existing analysis process. Various examples showed the analysis carried out will show more crosssectional aspects related to political interest and other variables. Thus, often the linkage leads to the ability to provide a sign as an estimate of possible implications.

The next sub-chapter from part three of this book explains the education aspect. For many people education influences on increasing political interest. So far, education has often been regarded as a universal solvent associated with various types of participation in politics ( Therefore, there is a theoretical explanation that assumes that education will influence people's interest in politics. This section primarily attempts to reveal the less profound educational effect that might be expected. This section shows a set of a panel of data showing that there is no high degree causal correlation of education to political interest. This section, however, succeeds in showing some good reasons for the hypothesis on education. The graphical analysis and the two statistical models in this section show consistent results that education does affect, the data being examined is political interest, but the effect is not large enough and usually lasts not too long.

It may indicate an inadvertent relationship to the hypothesis based on that political experience cannot be ignored as the biggest cause of increasing political interest. This is a warning to this conclusion, it shows the importance of civic education to other 
components of education. Without including the civic education aspect, it will be difficult to justify that the education aspect can indeed influence political interest.

The next part of the chapter talks about parent's aspects. Family members, especially parents, are the initial factors in the influence of socialization for children. This section provides an analysis of the relationship between children and parents on political interest, however, what is asked are similar questions related to the identification of a political party. Is it true that parents pass on their political interest to their children as the general hypothesis so far ?. The analysis begins with a description of the relation between political interests of parents and children, but it can still increase when parents do not influence their children. What is written in this section is seems support the notion that the mediation communication model is one way that allows parents to influence political interest adolescence (Shehata and Amnå 2017).

The explanation regarding that relationship as a characteristic of family functions. It including the family members who live together and the consistency of parental interest shows more clues that allow parents and children to influence each other. The next aspect that is explained in this section is in the form of an analysis which shows that due to the causality factor, the direction of influence shows different things and because of the influence that humans share many things in their life but last for a short time, efforts to determine the main causal factors will face a bigger challenge.

The analysis in this section shows that children are influenced by the political interests of their parents. They are more affected when their parents do it and they could lose it when their parents lose it too. it helps to distinguish two versions of parental influence: catch-up and on-going. The influence of parents in the form of catch-up usually occurs when the children are at a young age and at this time the children's political interest will be similar to the political interest level of parents all the time. This form of influence requires change even though the political interests of parents tend to be stable. The ongoing influence results in changes in children's political interests when or caused by changes in their parent's political interests.

In part 12, under the title Money, Health, and Happiness, this book tried to show is economic background differentiates influencing political interest. Based on data from Britain, Germany, and Switzerland, this book shows that economic inequality does not have a significant effect. While high-income people with high-level employment status appear to be more interested in politics, there is little evidence to suggest that ownership of economic resources based on income, employment status, or ownership of home causes people's interest in politics.

After taking into account the level of education, other components of socioeconomic status, including income and employment, it shows only a little effect on political interest. The workers have low political interest based on a few small counts. The income increases for the poor show that they have jobs and puts them in the position of people with high-status occupations which then diverts them from economically difficult situations, but it does not make them more interested in politics. These findings do not indicate support from the resource model when placed on political interest and are more consistent on the psychological model of interest, where ownership of material resources 
does not play an important role. What is conveyed in this paper shows that indeed economic factors have influence on the formation of a person's political interest where when it shifted it is very likely will also the shift of people's interest in politics (Newton and Giebler 2008).

Apart from analyzing the material aspects economically, this section also shows difficult situation someone experiences does not influence political interest. Parents who do not work or divorce do not have an influence on people's political interest, and even though the position of single parents shows a reduction, this has occurred in one out of three countries where the research was conducted.

Even the data also show that people who do not have a job have a little positive effect on political interest, especially in elderly people and health problems also make people more political interested. The two final findings are mainly concerned with the role that links politics and policy, in this case, in the context of the benefits of the health insurance system for those who do not have a job where may play a role in the formation of political interest.

Another thing that is shown in this section is that if people feel happy, it generally has the potential to increase political interest. Furthermore, people who feel satisfied with financial conditions and ownership of free time will influence increasing political interest.

Broadly speaking, this section presents data showing that economic inequality does not always affect inequality in political interest. When people with high income and job status are more interested in politics, there is little evidence to suggest that ownership of economic resources such as income, employment status, homeownership influences political interest. Employees are inherently low in political interest for several minor reasons. Increasing the income of the poor, ensuring that they get a job, and increasing their employment status will reduce their economic hard work but these conditions do not cause them to be more interested in politics.

\section{Conclution}

Finally, this chapter describes political attitudes and identities. In some psychological models, identity is used to explain political interests. Partisan causal effects tend to outweigh the other factors described in this book. Therefore, people tend to be attracted to politics in terms of personality, good upbringing, or long education. In short, if political interests are usually associated with self-governing classes because this segment is the population that contributes to collective decisions about how to run the state, this book chooses to focus primarily on explaining it outside the class. It makes this book even more interesting and succeeded in providing further explanations related to Political Interests properly.

\section{Conflicts of interest}

Author declares no conflict of interest. 


\section{References}

Aars, J., Christensen, D.A. (2018). Education and political participation: the impact of educational environments. Acta Politica. doi:10.1057/s41269-018-0101-5.

Newton, K; Giebler, H. (2008): Patterns of participation: Political and social participation in 22 nations, WZB Discussion Paper, No. SP IV 2008-201, Wissenschaftszentrum Berlin für Sozialforschung (WZB), Berlin

Prior, M. (2010). You've Either Got It or You Don't? The Stability of Political Interest over the Life Cycle. The Journal of Politics, Volume 72, Number 3, pp. 747-766.

Shehata, A., Erik, A. (2017). The Development of Political Interest Among Adolescents: A Communication Mediation Approach Using Five Waves of Panel Data. Communication Research. pp. 1-23. https://doi.org/10.1177/0093650217714360. 